\title{
CHANNEL SEDIMENTATION CAUSING BY GROUPING WAVES AND WIND WAVES AT THE FISHING PORT, JAPAN
}

\author{
Takehito Horie, Alpha Hydraulic Engineering Co., Ltd., horie@ahec.jp \\ Takashi Kamo, Alpha Hydraulic Engineering Co., Ltd., kamo@ahec.jp \\ Yasuji Nozaka, Hokkaido Government Department of construction, Japan, take4life2000@gmail.com \\ Hitoshi Tanaka, Tohoku University, tanaka@tsunami2.civil.tohoku.ac.jp
}

\section{INTRODUCTION}

Most of fishing ports in Hokkaido, Japan are located in the surf zone on the sandy beach. As a result, channel sedimentation has become a serious problem in many fishing ports. As an example, when planning a coastal structure to control littoral drift and nearshore current, annual maximum wave heights (wind waves) is used as the external forces condition in many cases. However, the effect as expected is not obtained on channel sedimentation at fishing ports in Hokkaido. To solve such a problem, it is necessary to understand the relationships between channel sedimentation and external force, and be able to reveal the developmental process of channel sedimentation. Then, field observation and theoretical approach (wave-to-wave analysis, spectral analysis, EOF analysis, et al) become important tools.

\section{DATA ANALYSIS AND RESULT}

Field observation was carried out at Kuroiwa fishing port is located at the inner of the Uchiura Bay (Figure 1). For two months in the autumn of 2015, we acquired continuous observation data (waves, velocities and bed level, et.al) with time interval of $0.2 \mathrm{~s}$. In addition, we conducted bottom sediment observation around fishing port. Field fixed point observations on waves and velocities at St. 1,2 and 3 were carried out by using Wave and Current Meter. The wave gage at St. 1 was installed at the depth of about 12 meters offshore. The bed level measurement at St. 4 was carried out by using an Acoustic Doppler Current Profilers with bottom tracking instrument. Figure 2 shows the time series of water level, wind wave, long periods waves, velocities and bed level, EOF mode of current speed respectively. During this observation term the low pressure (940 hpa) passed offshore. As the wind waves height increased, sand erosion also advanced. The point worth noting here is that the period of time in which grouping waves height had come, sand sedimentation had also advanced. On the other hands, the spectral width parameter ' $v$ ' during the sand sedimentation advanced was lower than that of during the sand erosion had occurred (not shown). Figure 3 shows the EOF analysis results of current fields. The EOF analysis is one of the useful statistic methods to compress complicated variability of current data both in space and in time into the fewest possible number of modes. The EOF mode1 during the period of time in which sand erosion occurred was different the EOF mode2 during the period of time in which sand sedimentation occurred.

\section{CONCLUSIONS}

From the above results, when planning a coastal structure to control littoral drift and nearshore current, not only wind waves but amount of wave energy is important.
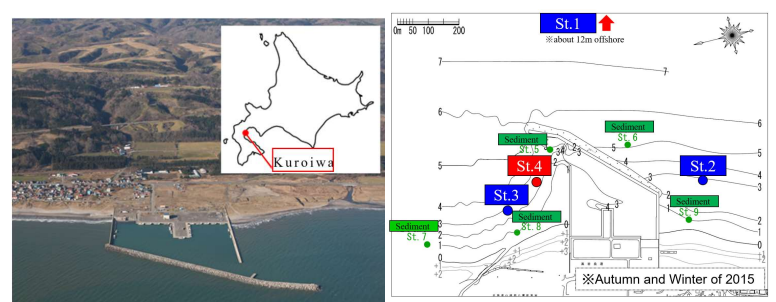

Figure 1 - Location of observation points (Kuroiwa)

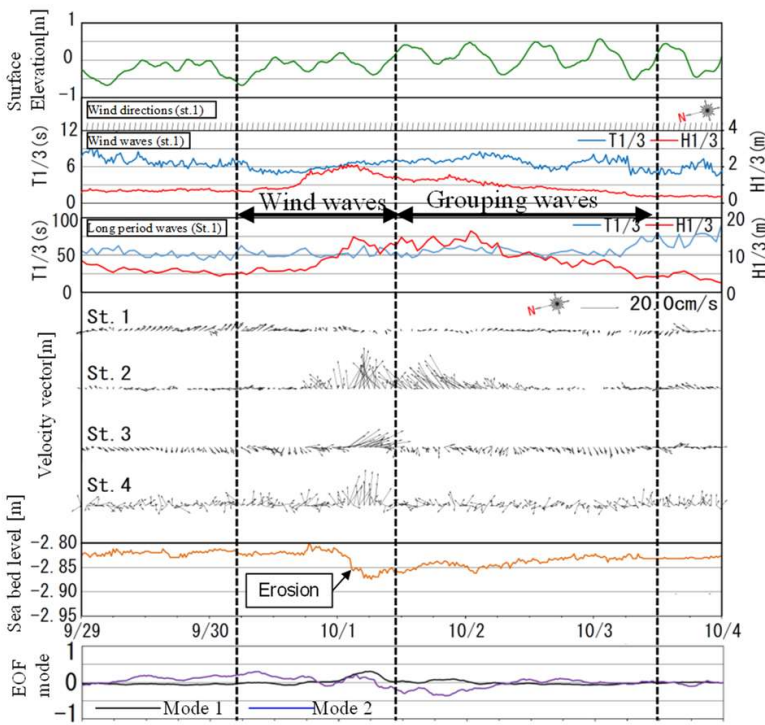

Figure 2 - The time series of surface elevation, wind waves long period waves, current speed, bed level change and EOF mode of current speed, respectively.

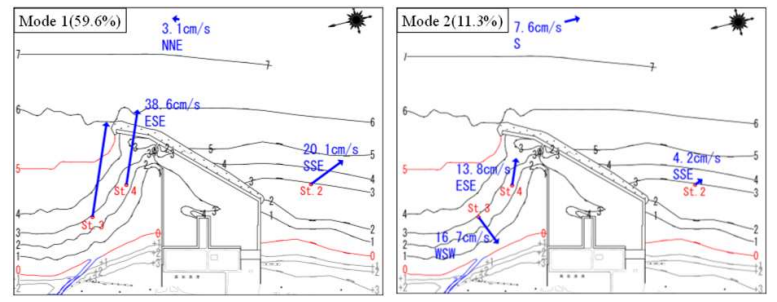

Figure 3 - EOF mode of current field

\section{REFERENCES}

Longuet-Higgins, M.S.,1984. Statistical properties of waves groups in a random sea state. Phil. Trans. Roy. Soc. London, A312:219-250. 